\section{Acknowledgments}

Portions of this work were supported by a Cooperative Research and Development Agreement between Vaccinex, Inc. and the University of Rochester.

1. Van den Eynde, B., Lethe, B., Van Pel, A., De Plaen, E. \& Boon, T. The gene coding for major tumor rejection antigen of tumor P815 is identical to the normal gene of syngeneic DBA/2 mice. J. Exp. Med. 173, 1373-1384 (1991).

2. Van Der Bruggen, P. et al. A gene encoding an antigen recognized by cytolytic T lymphocytes on a human melanoma. Science 254, 1643-1647 (1991).

3. Brichard, V. et al. The tyrosinase gene codes for an antigen recognized by autologous cytolytic T lymphocytes on HLA-A2 melanomas. J. Exp. Med. 178, 489-495 (1993).

4. Kawakami, Y. et al. Cloning of the gene coding for a shared human melanoma antigen recognized by autologous T cells infiltrating into tumor. Proc. Natl. Acad. Sci. USA 91 3515-3519 (1994)

5. Kawakami, Y. et al. Identification of a human melanoma antigen recognized by tumor-infiltrating lymphocytes associated with in vivo tumor rejection. Proc. Natl. Acad. Sci. USA 91, 6458-6462 (1994)

6. Boel, P. et al. BAGE: A new gene encoding an antigen recognized on human melanomas by cytolytic T lymphocytes. Immunity 2, 167-175 (1995).

7. Bloom, M.B. et al. Identification of tyrosinase-related protein 2 as a tumor rejection antigen for the B16 melanoma. J. Exp. Med. 185, 453-459 (1997).

8. Sahasrabudhe, D.M. et al. Shared T cell defined antigens on independently derived tumors. J. Immunol. 151, 6302-6310 (1993).

9. Collins, J.L., Patek, P.Q. \& Cohn, M. In vivo surveillance of tumorigenic cells transformed in vitro. Nature 299, 169-171 (1982).

10. Lin, Y., Patek, P.Q., Collins, J.L. \& Cohn, M. Analysis of immune surveillance of sequentially derived cell lines that differ in their tumorigenic potential. J. Natl. Cancer Inst. 74,
$1025-1030$ (1985)

11. Moss, B. Vaccinia virus: A tool for research and vaccine development. Science 252, 1662-1667 (1991)

12. Moss, B. Poxvirus expression vectors. Curr. Topics Microbiol. Immunol. 158, 25-38 (1992).

13. Merchlinsky, M., Eckert, D., Smith, E. \& Zauderer, M. Construction and characterization of vaccinia direct ligation vectors. Virology 238, 444-451 (1997)

14. Somogyi, P., Frazier, J. \& Skinner, M. Fowlpox virus host range restriction: Gene expression, DNA replication, and morphogenesis in nonpermissive mammalian cells. Virology 197, 439-444 (1993)

15. Peckham, I., Sobel, S., Comer, J., Jaenisch, R. \& Barklis, E. Retrovirus activation in embryonal carcinoma cells by cellular promoters Genes Dev. 3, 2062-2071 (1989).

16. Parker, K.C., Bednarek, M.A. \& Coligan, J.E. Scheme for ranking potential HLA-A2 binding peptides based on independent binding of individual peptide side-chains. J. Immunol. 152,163 (1994)

17. Kuwano, Y. \& Wool, I.G. The primary structure of rat ribosomal protein L3. Biochem. Biophys. Res. Commun. 187, 58-64 (1992).

18. Simonic, T. et al. cDNA sequence for bovine ribosomal protein $\mathrm{L} 3$ carrying a bipartite nuclear targeting motif, identified also in many other ribosomal proteins. Biochem. Biophys. Acta 1219, 706-710 (1994).

19. Overwijk, W.W. et al. Vaccination with a recombinant vaccinia virus encoding a 'self' antigen induces autoimmune vitiligo and tumor cell destruction in mice: Requirement for CD4+ T lymphocytes. Proc. Natl. Acad. Sci. USA 96, 2982-2987 (1999).

20. Targoni, O.S. \& Lehmann, P.V. Endogenous myelin basic protein inactivates the high avidity T cell repertoire. J. Exp. Med. 187, 2055-2063 (1998).

21. Harrington, C.J. et al. Differential tolerance is induced in T cells recognizing distinct epitopes of myelin basic protein. Immunity 8, 571-580 (1998)

22. Olsen, S.R. \& Uhler, M.D. Isolation and characterization of cDNA clones for an inhibitor protein of CAMP-dependent Protein Kinase. J. Biol. Chem. 266, 11158-11162 (1991).

\title{
ON THE MARKET
}

MICROARRAY PARAPHERNALIA

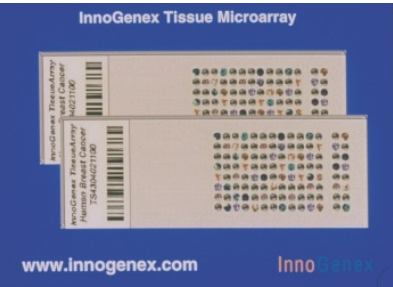

Tissue microarrays for highthroughput screening.

InnoGenex has introduced tissue microarrays for high-throughput screening of the in situ gene expression for target validation. The microarrays are available from diseased and normal human tissues, and mouse and rat normal tissues. These histologically characterized slides are intended for the rapid screening of in situ differential expression of genes, identifying novel antibody markers, animal model studies, or for any other application that would use traditional tissue sections. Low-density arrays contain 20 to 50 elements per slide; high-density arrays have 100-200.

Tel. (+1) 925-543-1400

Fax (+1) 925-543-1405

www.innogenex.com

The new NEN TSA microarray labeling and detection kits are designed to allow researchers to use as little as $0.5-1.0 \mu \mathrm{g}$ total RNA starting sample - a 100- to 200fold decrease compared to conventional cDNA labeling protocols, says Perkin-Elmer Life Sciences. This is said to allow differential gene expression analysis on minute samples, such as tissue biopsies. The kits enable two-color fluorescent hybridization on the same slide and come in three versions: one that contains enough reagent for 10 labeling reactions, one for 40 labeling reactions, and one that contains reagents for 10 labeling reactions, two 2,400-gene microarray glass slides and two practice slides.

Tel. (+1) 617-482-9595

Fax $(+1)$ 617-482-1380

www.perkinelmer.com/lifesciences

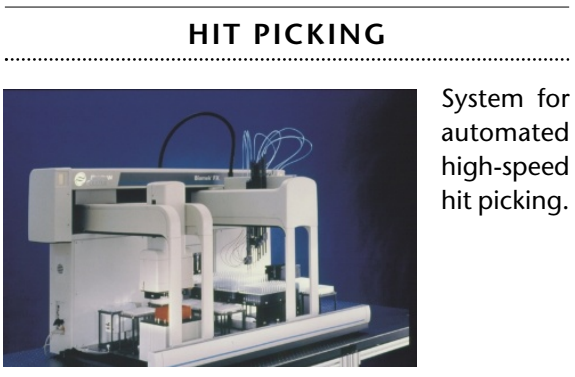

The new Biomek FX Hit Picking Solution from Beckman Coulter is an automated system designed to rapidly transfer 'hits' for subsequent compound screening applications. A new software wizard provides a quick and easy tool for developing the appropriate labware handling and pipetting methods. The Biomek FX system can be configured with one or two liquid handling arms and a flexible array of stations. Pipetting options include multichannel and the new independent eight-channel pipettors, both of which can be integrated into a single system. The former is available with interchangeable 96channel, or new 384-channel disposable tip pipetting heads. Automated labware posi- tioners, such as a shaker, stirrer, tip washer and barcode reader, facilitate the optimum configuration of labware on the deck for each assay or protocol. All of the supported labware functions can be performed directly on the deck, in up to 20 plate positions. Stacker carousels can be added for increased walkaway automation.

Tel. (+1) 714-871-4848

Fax (+1) 714-773-6611

www.beckmancoulter.com

GENE EXPRESSION ANALYSIS

Imaging Research, a majority owned subsidiary of Amersham Pharmacia Biotech, has announced today the availability of version 6.0 of ArrayVision - software for the analysis of gene expression arrays. This new version incorporates new features that enable true auto-alignment for high-throughput fluorescent array processing and automatic export to ArrayStat, the company's statistical informatics program for gene expression arrays. ArrayVision 6.0 features automation wizards and alignment algorithms for walk-away batch processing. The program automatically finds the array, calculates array rotation, positions the template and aligns each spot for analysis. Additional features include simplified gene name import for clone tracking, and automatic and rapid export to a variety of file formats, including XML and Microsoft Excel.

Tel. (+1) 905-688-2040

Fax (+1) 905-685-5861

www.imagingresearch.com 